\title{
PASD1: A Promising Target for the Immunotherapy of Haematological Malignancies
}

Ghazala Khan ${ }^{1}$, Frances Denniss ${ }^{2}$, Ken I Mills ${ }^{3}$, Karen Pulford ${ }^{4}$ and Barbara-ann Guinn ${ }^{1,2 *}$

${ }^{1}$ Department of Life Sciences, University of Bedfordshire, Park Square, Luton, LU1 3JU, UK

${ }^{2}$ Department of Haematological Medicine, The Rayne Institute, King's College London School of Medicine SE5 9NU, UK

${ }^{3}$ Centre for Cancer Research and Cell Biology, Queens University Belfast, Belfast, BT9 7BL, UK

${ }^{4}$ Nuffield Division of Clinical Laboratory Sciences, University of Oxford, John Radcliffe Hospital, Oxford, OX3 9DU, UK

\begin{abstract}
In general, there is a lack of good immunotherapy targets within the spectrum of haematological malignancies. However haematopoietic stem cell transplants and continuing antigen discovery have allowed further insight into how further improvements in outcomes for patients might be achieved. Most patients with haematological malignancies can be treated with conventional therapies such as radio- and chemotherapy and will attain first remission. However the removal of residual diseased cells is essential to prevent relapse and its associated high mortality. PASD1 is one of the most tissue restricted cancer-testis (CT) antigens with expression limited to primary spermatagonia in healthy tissue. However, characterisation of PASD1 expression in cancers has been predominantly focussed on haematological malignancies where the inappropriate expression of PASD1 was first identified. PASD1 has one of the highest frequencies of expression of all CT antigens in acute myeloid leukaemia, with some suggestion of its role as a biomarker in diffuse large B-cell lymphoma. Here we describe the characterisation of the function and expression patterns of PASD1 in cell lines and primary tissues. Development of DNA vaccines targeting PASD1 epitopes demonstrate effective ex vivo T-cell responses in terms of IFNy secretion and tumour cell killing. Of particular note these vaccines have led to the destruction of cells which process and present endogenous PASD1 indicating that effectively primed CTLs could kill PASD1-positive tumour cells.
\end{abstract}

Keywords: PASD1; Immunotherapy; Cancer; Tumour antigen; Cancer-testis antigen

Abbreviations: AA: Amino-Acid; AML: Acute Myeloid Leukaemia; CT: Cancer-testis; CTL: Cytotoxic T-lymphocyte; DLBCL: Diffuse Large B-cell Lymphoma; IFN $\gamma$ : Interferon-gamma; MLR: Mixed Lymphocyte Reaction; MM: Multiple Myeloma; PASD1: Per Arnt Sim Domain Containing 1; pMHC: Peptide Major Histocompatibility Complex; RT-PCR: Reverse Transcription Polymerase Chain Reaction; RQ-PCR: Real-time Polymerase Chain Reaction; SEREX: Serological Identification of Antigens by Recombinant Expression Cloning.

\section{Introduction}

The quest to identify novel antigens has been the focus of a number of studies over the last four decades [1,2]. Autologous typing had been used to identify some antigens including alpha fetoprotein (in hepatoma and germ cell tumours), carcinoembryonic antigen (CEA) (in gastrointestinal cancers), prostate-specific antigen (in prostate cancer), cancer antigen 125 (CA-125) (in ovarian cancer) and AU (in melanomas)(reviewed in $[3,4]$ ). However the technique has limitations, including a requirement that the cells under examination can be cultured. Furthermore, the recognition of antigens by low titre antibodies in patients often prevents their further characterisation. The Boon group developed representational difference analysis and were successful in identifying a number of cancer-testis (CT) antigens from melanoma patients, the MAGE family of CT antigens, and one antigen from renal cancer, RAGE [5,6].

In 1995 Sahin et al. described the use of the serological identification of antigens by recombinant expression cloning (SEREX) to discover antigens in a range of cancer tissues $[7,8]$. In this technique patient immunoglobulins (IgG) from peripheral blood sera were used to immunoscreen cDNA from tumours, cell lines or normal testis tissues in the form of polypeptides on the surface of the phage. There are over 2,000 tumour antigens detailed in the Cancer Immunome database (http://ludwig-sun5.unil.ch/CancerImmunomeDB/) each identified using the SEREX technique [9]. SEREX was validated by the identification of known antigens such as SSX2 (synovial Sarcoma X 2) [10], mutated p53 [11] and the AKT oncogene [12]. To maximise the chance of finding new $\mathrm{CT}$ antigens cDNA libraries made from healthy testis cDNA have been immunoscreened with patient sera. This has led to the identification of a number of CT antigens including cTAGE-1, NY-ESO-1, SSX2 $[13,14]$ and PASD1 $[15,16]$. One-third of all antigens identified by SEREX were found to be novel and have led to the development of a number of clinical trials, most notably those targeting NY-ESO-1 positive tumour cells $[17,18]$.

Tumour antigens are classified into the following categories: CT, mutational, differentiation, amplified/overexpressed, splice variant and viral antigens [7]. CT antigens show restrictive expression, their presence only in tumours and in testis rendering them very attractive therapeutic targets. The testis is an immunologically protected site i.e. lacking in MHC class I expression, therefore targeting CTAs should not lead to catastrophic auto-immune responses against healthy tissue [19].

The debate now remains as to whether we have found enough tumour antigens and whether there is a need to continue the search for

*Corresponding author: Barbara-ann Guinn, Department of Life Sciences University of Bedfordshire, Park Square, Luton, LU1 3JU, UK, Tel: +44 1582 743573; E-mail: barbara.guinn@beds.ac.uk

Received August 08, 2013; Accepted September 30, 2013; Published October 10,2013

Citation: Khan G, Denniss F, Mills KI, Pulford K, Guinn B (2013) PASD1: A Promising Target for the Immunotherapy of Haematological Malignancies. J Genet Syndr Gene Ther 4: 186. doi:10.4172/2157-7412.1000186

Copyright: ( 2013 Khan G, et al. This is an open-access article distributed under the terms of the Creative Commons Attribution License, which permits unrestricted use, distribution, and reproduction in any medium, provided the original author and source are credited. 
more. Supported by the National Cancer Institute, Cheever et al. [20] reported a short-list of antigens which demonstrated properties that would support their further investigation as targets for immunotherapy clinical trials. From a list of 75 antigens identified as the most promising for translational therapies, the authors ranked antigens by criteria such as, but not limited to, therapeutic function, immunogenicity, their role in cancer development, specificity to cancer, expression levels and percent of antigen-positive cells within a cancer type, stem cell expression, number of patients with antigen-positive cancers, number of antigenic epitopes and the cellular location of antigen expression. The aim was to focus funding and research effort on antigens that showed the most potential to make it through to clinical trials and benefit patients. However in some cancers, and most notably haematological malignancies, few of the antigens on this short-list were expressed with a frequency that would justify targeting them in clinical trials.

Today techniques including the Serological identification of antigens by Recombinant Expression cloning (SEREX) [8], Serological Proteome Analysis (SERPA) [21] and peptide elution from MHC for mass spectrometry analysis [22] are commonly used to identify which antigens are important in a given cancer. There are of course pros and cons to each including cost and labour intensity. Most of the focus concerns tumour types which lack suitable targets for immunotherapy and for which conventional or current therapies still do not overcome poor survival rates. An additional major benefit of new antigen identification is that such antigens can provide invaluable insight into disease mechanisms [23], act as biomarkers of disease stage [24] and predict survival rates at disease presentation [25-28].

Here we review the CT antigen, PASD1 and whether it has the hallmarks of an "ideal" cancer antigen which meets the criteria as outlined by Cheever et al. [20]. If so then this would justify the progression of PASD1 into clinical trials.

\section{The PASD1 Gene}

The CT antigen database (http://www.cta.lncc.br) indicates there are more than $250 \mathrm{CT}$ antigens categorised as either CT-X and located on the X-chromosome or located on an autosome $[29,30]$. Approximately $10 \%$ of genes on the X-chromosome appear to be CT antigens $[29,31,32]$. Antigens on the X chromosome, such as the MAGE antigens, tend to group in families and are usually expressed in the testes in a co-ordinated way [2,31]. However spermatagonia and cancer share a number of features including rapid proliferation and global promoter hypomethylation and as such share expression of a number of CT antigens. Like many CT antigens, the gene encoding PASD1 also maps to the X chromosome at Xq28 [33], near NY-ESO-1 and LAGE-1.

Two SEREX antigens were found to be encoded by the per ARNT SIM (PAS) domain containing 1 (PASD1) gene: OX-TES-1, identified through the immunoscreening of a healthy donor testis cDNA library with diffuse large B-cell lymphoma (DLBCL) [34] and the SEREX antigen GKT-AML20 found through the immunoscreening of a healthy donor testis cDNA library with acute myeloid leukaemia (AML) sera [15].

Although PASD1 is transcribed from 16 exons [35], the PASD1_v1 transcript is longer than the $P A S D 1 \_v 2$ transcript due to a retained intron between exons 14 and 15 . The presence of a stop signal in the retained intron leads to the translation of a shorter PASD1-1 protein (PASD1a) from PASD1_v1. Such retained introns are relatively common in cancer $[36,37]$ and have been described previously in tumour antigens [38]. The PASD1_v1 transcript encodes a 639 aa protein product named PASD1a while PASD1_v2 encodes the PASD1b protein which is 773 aa long, with the first 638 aa being common to both proteins [35].

The PASD1 protein contains two PAS domains in the $\mathrm{N}$-terminal region between aa 32-94 and aa 41-137 [35]. PAS domains are found on proteins which are critical regulators of developmental and metabolic processes, including transcriptional responses to stimuli such as hypoxia and environmental pollutants, mediated by factors including hypoxia inducible factors (HIF- $\alpha$ ) and the dioxin (aryl hydrocarbon) receptor (DR) [39]. A family of 23 known members, the PAS domain genes contain a basic helix-loop-helix (bHLH) sequence, and are involved in signal transduction in a wide number of organisms [40]. Incorrect signalling by PAS domains has been associated with diseases including heart arrhythmias [41] as well as myocardial and cerebral ischemia [42].

PASD1 homologues have been identified in 16 additional species including gorilla, cow, chicken and mouse and referred to as GM1141 (Entrez Gene). In mice, PASD1 shows most similarity to the CLOCK gene essential for circadian behaviour. Circadian rhythms are biological processes that show endogenous oscillations which are adjusted to the environment-often natural light levels. Such processes may include daily fluctuating hormone levels or sleeping patterns.

We have previously examined whether PASD1 levels of expression were affected by the cell cycle. Briefly we synchronised K562 cells using either serum starvation $\left(10^{5}\right.$ cells $/ \mathrm{ml}$ in $0.1 \%$ foetal calf serum for 5 days to cause a block at $\mathrm{G}_{0}$ ) or using $0.3 \mathrm{mM}$ hydroxyurea for 3 days to block at the $G_{1} / S$ interface of the cell cycle, as demonstrated by flow cytometry [43]. We detected no significant changes in the number of PASD1 expressing cells within the synchronised population over a 24hour period (with hourly sampling). However PASD1 expression was only found within a subset(s) of the K562 cell population throughout the period of analysis.

\section{Sub-Cellular Localisation of PASD1 Expression in Healthy and Cancerous Tissue}

PASD1 expression in normal tissues was restricted to the nuclei of a subpopulation of spermatogonia [44] and labelling intensity decreased with maturity of the spermatogoa. Both PASD1-1 and PASD1-2 monoclonal antibodies gave comparable labelling of testis tissue.

In a cohort of haematological malignancy derived cell lines, the sub-cellular localisation of PASD1, as determined by immunostaining with monoclonal antibodies, was variable [44] (Table 1). Cooper et al. showed that in the non-germinal centre DLBCL-derived cells OCI-Ly3 [45] PASD1-1 strongly labelled the cell membrane and cytoplasm while there was no staining of these cells with PASD1-2. KM-H2, established from the pleural effusion of a patient with Hodgkin's disease of mixed cellular type [46] and the mantle cell lymphoma (MCL)-derived cell line Granta519 showed nuclear staining with PASD1-1 and PASD1-2 antibodies while strong cytoplasmic labelling with PASD1-2 was also observed in a subpopulation of Granta519 cells. K562 cells derived from a patient with myeloid leukaemia [47] and the Thiel multiple myeloma (MM) cell line all exhibited nuclear staining. The detection of nuclear staining was not unexpected and likely reflects the presence of a nuclear localisation signal in the common region of the PASD1-1 and PASD1-2 proteins. Expression of PASD1 was also demonstrated in the FEDP (ALK-negative anaplastic large-cell lymphoma) cell line.

The antibodies PASD1-1 and PASD1-2 both label the $100 \mathrm{kDa}$ 
Citation: Khan G, Denniss F, Mills KI, Pulford K, Guinn B (2013) PASD1: A Promising Target for the Immunotherapy of Haematological Malignancies. J Genet Syndr Gene Ther 4: 186. doi:10.4172/2157-7412.1000186

Page 3 of 8

A.

\begin{tabular}{|c|c|c|c|}
\hline Cell line name and tissue derived from & Method of analysis & Frequency and subcellular localisation of PASD1 expression & Reference \\
\hline $\begin{array}{l}\text { FEDP (ALK-negative anaplastic large-cell } \\
\text { lymphoma) }\end{array}$ & Immunostaining & PASD1-1, but not PASD1-2, positive & [44] \\
\hline G361 (melanoma) & Tissue arrays & PASD1 positive & [35] \\
\hline Granta519 (mantle cell lymphoma cell line) & Immunostaining & $\begin{array}{l}\text { Nuclear staining with PASD1-1 and PASD1-2 antibodies, while } \\
\text { strong cytoplasmic labelling with PASD1-2 was also observed in a } \\
\text { subpopulation of Granta519 cells. }\end{array}$ & [44] \\
\hline H1299 (lung cancer) & $\begin{array}{c}\text { RQ-PCR } \\
\text { Immunostaining }\end{array}$ & $\begin{array}{c}\text { PASD1 positive } \\
>99 \% \text { expression of PASD1-2 }\end{array}$ & $\begin{array}{l}{[15]} \\
{[63]}\end{array}$ \\
\hline Hn5 (head and neck cancer) & $R Q-P C R$ & PASD1 positive & [15] \\
\hline Jurkats ( $T$ cell leukaemia) & $R Q-P C R$ & PASD1 positive & [15] \\
\hline K562 (CML) & Immunostaining & $17.6 \pm 3.6 \%$ nuclear staining & [63] \\
\hline $\begin{array}{l}\text { KH-M2 established from the pleural effusion } \\
\text { of a patient with Hodgkin's disease of mixed } \\
\text { cellular type }\end{array}$ & Immunostaining & Nuclear staining with PASD1-1 and PASD1-2 antibodies & [44] \\
\hline KMS-12-BM MM cell line & \multirow{2}{*}{ Immunostaining } & \multirow{2}{*}{$\begin{array}{l}\text { Expression of PASD1-1 and PASD 1-2. Expression in }>95 \% \text { nuclei of } \\
\text { cells }\end{array}$} & \multirow{2}{*}{ [48] } \\
\hline MOLP-8 MM cell line & & & \\
\hline $\begin{array}{c}\text { OCI-LY3 (non-germinal centre diffuse large } \\
\text { B-cell lymphoma) }\end{array}$ & Immunostaining & $\begin{array}{l}\text { PASD 1-1 strongly labelled the cell membrane and cytoplasm while there } \\
\text { was no staining of these cells with PASD1-2 }\end{array}$ & [44] \\
\hline Thiel (MM) & \multirow{2}{*}{ Immunostaining } & \multirow{2}{*}{$\begin{array}{l}\text { Nuclear staining PASD } 1-1 \text { and PASD1-2 staining } 5 \text { of } 11 \text { multiple } \\
\text { myeloma cell lines, of which THIEL and RPMI8226 expressed both } \\
\text { PASD1 mRNA and protein. }\end{array}$} & \multirow{2}{*}{$\begin{array}{l}{[49]} \\
{[44]}\end{array}$} \\
\hline RPMI8226 (MM) & & & \\
\hline SW480 (colon cancer) & $\begin{array}{l}\text { Tissue arrays RQ-PCR } \\
\text { Immunostaining and flow } \\
\text { cytometry }\end{array}$ & $\begin{array}{c}\text { PASD1 positive } \\
\text { Expression of PASD1-2 }\end{array}$ & {$[15,35,63]$} \\
\hline
\end{tabular}

B.

Tissue

Expression in 25 of 68 solid tumours

A range of normal tissues including brain, liver, kidney, placenta, breast, uterus or ovary

4 of $12 \mathrm{AML}$ patients, and 1 of $6 \mathrm{CML}$ patients

Normal testicular tissues expression was only found in the nuclei of a subpopulation of spermatogonia. Labelling intensity decreased with maturity of the spermatogoa.

Examples of PASD1-1: 21 of 51 DLBCL, 4 of 9 mantle cell lymphoma, 4 of 15 follicular lymphomas, 4 of 12 Burkitt's lymphoma. PASD1-2: 11 of 52 DLBCL, 2 of 4 MM, 4/10 peripheral T cell lymphoma and a range of other tumour cells from patients with haematological malignancies. $41 \%$ overall. PASD1-1 was mostly cytoplasmic and weak nuclear staining in DLBCL and MM. Stronger labelling towards the periphery of the tumour.PASD1-2 was nuclear staining.

14 of 16 primary MM samples including 9 presentation and 7 previously treated cases

Two of four primary MM tumour samples

PASD1 (22/25) cell lines derived from $21 \mathrm{~B}$ - and 4 T-cell malignancies

$3.4 \%$ of 320 newly diagnosed and 264 relapse cases of MM

Not found in 78 basal cell carcinoma

\begin{tabular}{|c|c|}
\hline Technique & Reference \\
\hline Probing Northern blot arrays & {$[35]$} \\
\hline RT-PCR and ICC & {$[15,44]$} \\
\hline RT-PCR and RQ-PCR & {$[15]$} \\
\hline Immunostaining & {$[44]$} \\
\hline Immunostaining & {$[44]$} \\
\hline RQ-PCR & \\
\hline ICC & {$[49]$} \\
\hline RT-PCR & {$[49]$} \\
\hline Microarray using Affymetrix \\
GeneChips & {$[50]$} \\
RQ-PCR & {$[51]$} \\
\hline
\end{tabular}

AML: Acute Myeloid Leukaemia; CML: Chronic Myeloid Leukaemia; DLBCL: Diffuse Large B-cell Lymphoma; MM: Multiple Myeloma

Table 1: PASD1 expression in human cells $(\mathbf{A})$ cell lines and $(\mathbf{B})$ tissues.

PASD1b protein in lysates from Thiel and KM-H2 cells by Western blotting, while the PASD1-1 antibody also identified a 40kDa protein in OCI-Ly3 and FEPD cells. The PASD1-2 antibody did not recognise any proteins in these two cell lines. This $40 \mathrm{kDa}$ protein is smaller than was predicted from the translation of the PASD1_v1 or PASD1_v2 transcripts and suggests the presence of an additional novel PASD1 isoform in these cells, not least due to its cytoplasmic expression [44]. In 2010, Joseph-Pietras et al. showed that in addition to a full length PASD1 protein found in Thiel cells there was a higher molecular weight protein labelled by the antibody to PASD1-2 in KMS-12-BM again suggesting the existence of additional variants of PASD1 [48].

\section{Comparison of the Expression of PASD1 with Other CTs}

PASD1 mRNA expression was seen to be highest in G361 (melanoma) and SW480 (colorectal adenocarcinoma) of the nine cell lines tested on matched tumour/normal tissue Northern blot arrays
[35]. Using real-time polymerase chain reaction (RQ-PCR), PASD1 transcripts expression were detected in the K562 (chronic myeloid leukaemia (CML), Jurkats (T-cell leukaemia) and H1299 (lung cancer) cell lines. PASD1 levels were significantly higher in the lung cancer cell line H1299 (88 times higher than K562 and more than twice the levels seen in the testis) [15]. PASD1 transcripts have also been found in $33 \%$ (4 of 12) AML patients, 1 of 6 CML patients and 4 of 16 cell lines, (Hn5, Jurkats, K562 and H1299) by RQ-PCR [15] as well as in primary MM samples at presentation and following treatment [49]. Reverse transcription (RT)-PCR analysis of the expression of 32 antigens in cell lines derived from $21 \mathrm{~B}$ - and $4 \mathrm{~T}$-cell malignancies indicated that eight CT genes had the broadest expression profiles. Of the 25 cell lines examined expression of CT antigens was found as follows: $S p 17(25 / 25$, 100\%), PRAME (25/25, 100\%), CSAGE (24/25, 96\%), PASD1 (22/25, 88\%), CAGE/DDX53 (19/25, 76\%), CTAGE1 (19/25, 76\%), HAGE/ DDX43 $(16 / 25,64 \%)$ and PLU-1/JARID1B (15/25, 60\%) [50].

Previous data also showed PASD1 expression in 25 of 68 solid 
tumours on matched tumour/normal tissue array [35]. Of note in this study, the highest levels of hybridisation of PASD1 cDNA was observed with stomach and uterine cancer samples when compared with normal adjacent tissues samples.

Cooper et al. (2006) [44] also showed PASD1 expression in 21 of 51 diffuse DLBCL patients, 4 of 9 MCL, 4 of 15 follicular lymphomas and a range of other tumour cells taken from patients with haematological malignancies. Notably PASD1a expression, was found more often than PASD1b, and was often cytoplasmic. PASD1 protein expression has been shown by immunostaining 2 of 4 primary MM tumour samples [49] and 5 of $11 \mathrm{MM}$ cell lines, of which THIEL and RPMI8226 expressed both PASD1 mRNA and protein.

Despite these results, $P A S D 1$ did not achieve the elevated expression in the required cut-off of $\geq 5 \%$ of 320 newly diagnosed and 264 relapse MM patients when analysed by Affymetrix GeneChips. In contrast 87 of the $123 \mathrm{CT}$ antigens analysed did merit further evaluation in this study by van Duin et al. [51]. We have also found variation between the relative expression of antigens on microarray [52] compared with detection of antigens by SEREX [15] in AML samples. The results of Van Duin may, in part, be explained by the propensity for probe sets on microarrays to favour 3' transcripts, the most variable end of most transcripts, especially for genes like PASD1 which are anticipated to have multiple transcriptional variants. In addition PASD1 is not present on some microarray chips including U133A perhaps leading to a small under estimate in the frequency of expression. In addition PASD1 transcript expression was not found in 78 basal cell carcinoma by RQ- PCR [53].

\section{PASD1 as a Biomarker}

Insufficient evidence is available to determine whether PASD1 is a suitable prognostic biomarker. To date, two of the four DLBCL patients in whom antibodies to PASD1 were found also had poor survival markers [35]. Germinal centre markers CD10 and BCL6 are associated with better survival while expression of the non-germinal centre marker MUM1 suggests worse overall survival [54]. Patients with non-germinal centre type showed serum reactivity with PASD1, and PASD1_v2 expression was restricted to non-germinal cell lines.

\section{Immune Responses to PASD1}

\section{Humoral immune responses}

Humoral responses to PASD1 have been demonstrated through the use of SEREX $[15,16]$ indicating that at disease presentation 4 out of 10 patients with DLBCL, 6 out of 17 AML and 1 of 6 CML patients had already mounted cellular immune responses releasing antibodies into the peripheral blood volume of these patients. Similar antibody responses were not found in the periphery of 20 and 10 healthy donors in these studies, respectively. The question remains why these antibody responses were insufficient to kill PASD1 positive tumour cells. One theory is that tumour cells may induce some immune response in the mid-stages of the cancers' development, when there are enough tumour cells to be seen by the immune response, but as these tumour cells proliferate they downregulate the immune system of the patient and escape effective killing [55]. Many of the antigens recognised by SEREX are nuclear transcription factors with low immunogenicity. It is proposed that those antigens with high enough immunogenicity would have already induced tumour cell killing. Only antigens with poor immunogenicity would have escaped immune surveillance. Immunotherapy, therefore, offers a way to enhance immune recognition of CT and tumour-associated antigens by the immune system and induce effective residual tumour cell killing.

Indeed we have shown that the elevated expression of some tumour antigens at disease presentation is associated with enhanced patient survival $[25,27,28]$. We have proposed that, during conventional therapy, the resulting tumour lysis would lead to inflammation and provide the requisite "danger signals" [56] which in turn leads to the induction of effective anti-tumour immune responses. Patients with elevated antigen expression would be better able to induce immune responses which would lead to the killing of antigen positive tumour cells and subsequent epitope spreading [57]. There is increasing evidence that chemotherapy may have a synergistic effect on the immune response to support this possibility [58].

\section{$\mathrm{T}$ cell responses}

T-cell immunogenic epitopes within PASD1a and PASD1b were identified using the TEPITOPE [59], SYFPEITHI [60] and BIMAS [61] prediction programmes (Table 2 and Figure 1). The capacity of the MHC class I epitopes to bind HLA-A2 were confirmed using T2 assays (assay detailed in [62]) which can predict A2-peptide off-rates. T2 cells are TAP-deficient and only stabilize the HLA-A*0201 molecule on the surface of the cell when binding peptide. The avidity and halflife of peptide binding to $\mathrm{MHC}$ were detected by fluorescent activated cells (FACs) analysis using anti-HLA-A2. In each case the criteria used required that epitopes under investigation should not be similar to epitopes from other known human proteins. A cut-off of similarity across the 9-10 a.a. peptides was $\geq 40 \%$ to any other known human protein and utilisation of SYFPEITHI predicted epitopes in favour of BIMAS ones [63].

Cytotoxic T cells are considered to be the major effector cells in tumour immunity. A cytotoxic T-cell (CTL) response to PASD1 could be detected in DLBCL patients [64]. Furthermore, interferon-gamma $(\mathrm{IFN} \gamma)$ release was detected in 21 out of 29 HLA-A ${ }^{*} 0201$-positive DLBCL patients following short-term culture of their peripheral blood mononuclear cells stimulated with five HLA-A ${ }^{\star} 0201$-restricted PASD1 peptides. However, there was no response in the 21 patients who were HLA-A ${ }^{\star} 0201$-negative.

CD4 $\mathrm{T}$ helper cells are known to promote immunity in a number

\begin{tabular}{|c|c|c|c|}
\hline Name of epitope & MHC binding & Peptide sequence & Immunogenicity \\
\hline PASD1(1) $)_{38-47}$ & HLA-A*0201 & QLLDGFMIT & IFNy secretion following MLR with patient T cells [64]. Demonstrated by IFNy ELISpot and CTL \\
assays ex vivo [48]
\end{tabular}

Table 2: Details of the most immunogenic PASD1 epitopes 


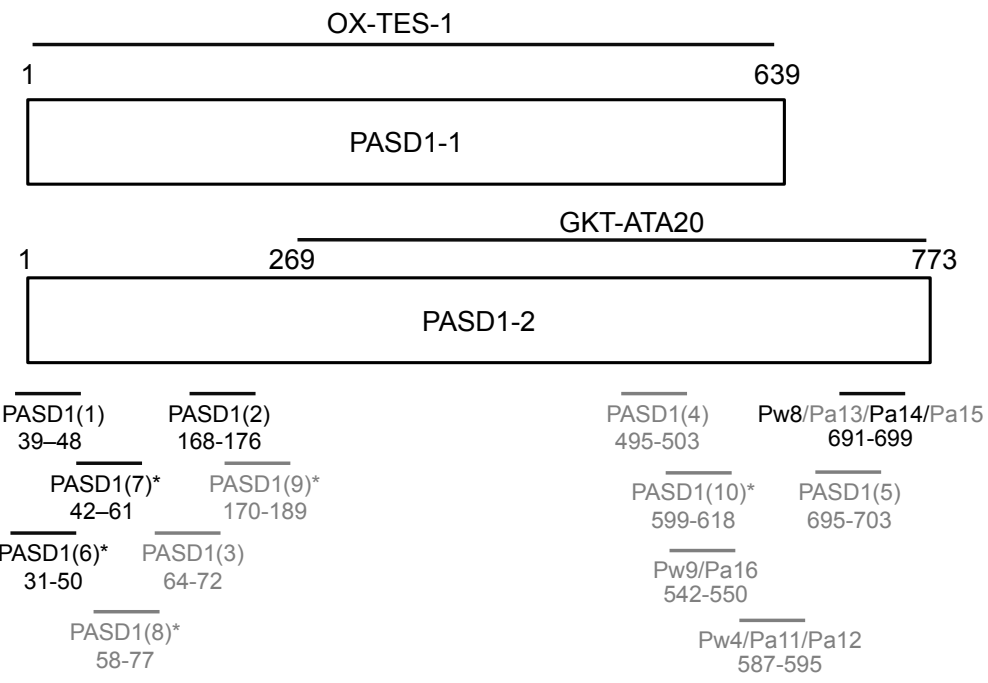

*indicates MHC class II binding epitopes.

Figure 1: Location of the immunogenic PASD1 epitopes within the PASD1-1 and PASD1-2 proteins. OX-TES-1 and GKT-AML20 are the cDNAs identified by SEREX immunoscreening of a testis library with DLBCL and AML sera respectively $[15,16]$. Grey text indicates potential epitopes in PASD1 which have not been investigated in vivo.

of ways such as stimulating production of antibodies. CD4 responses against PASD1 epitopes were investigated by Ait-Tahar et al. [65] in patients with DLBCL. They showed that immunogenic PASD1 epitopes predicted to bind several class II DR beta 1 alleles were able to induce $\mathrm{CD} 4^{+} \mathrm{T}$ helper responses to PASD1-positive cells from patients with DLBCL. Two of the five peptides (PASD1(6) and PASD1(7)) were shown to be immunogenic in 14 of the 32 patients tested and T-helper cell lines generated from two patients were able to lyse PASD1 positive cell lines derived from haematological malignancies. $\mathrm{CD} 4^{+} \mathrm{T}$ helper cell lines raised from two patients were able to lyse PASD1-positive tumour cell lines corroborating that these $\mathrm{T}$ cells recognized intracellular expressed PASD1. The PASD1-negative cell line was not lysed.

None of the seven MHC class I binding nonamers (named sequentially $\mathrm{Pw} 4$ through to $\mathrm{Pw} 10$ ) identified using predictive programmes were able to stabilise HLA-A ${ }^{\star} 0201$ in T2 assays and all had poor SYFPEITHI scores [63]. However, modification of one of the anchor residues at a.a. 2 or 9 (to a lysine, valine or isoleucine) did lead to epitopes with improved SYFPEITHI scores and enhanced and/or extended periods of binding to HLA-A*0201 in T2 assays. One of these modified peptides, named Pa14, was shown to be able to stimulate patient $\mathrm{T}$ cells. This caused a very limited expansion in $\mathrm{CD}^{+} \mathrm{T}$ cell numbers from two of three HLA-A*0201 positive, PASD1positive AML patient samples. This corresponds with the findings of others [66] who also found limitations in the expansion that can be achieved with AML T cells ex vivo. A 2-3 week limited expansion is the maximum that has been achieved prior to cell death. Reasons for the limited responses may be due to the presence of myeloid suppressor cells in mixed lymphocyte assays [67], interleukin-6 (IL-6) secretion by myeloid leukaemia cells [68] and/or defects in T cell populations in myeloid leukaemia patients [69]. However stimulation of $\mathrm{T}$ cells from a single colon cancer patient, in this study, led to a substantial increase in the number of Pa14-specific T cells to $13.6 \%$ of the CD8 ${ }^{+}$ cell population after 4 rounds of weekly $\mathrm{Pa} 14$ stimulation, with $\mathrm{Pa} 14$ specific IFN $\gamma$ responses being evidenced [63].

The combined treatment of conventional (surgery and chemotherapy) and immunotherapy in a patient with metastatic melanoma has been recently described [70]. Palliative treatment with radiation had eliminated the patient's primary tumour and in-transit non-irradiated metastases. This abscopal effect was shown to be due, at least in part, to a systemic anti-MAGEA3 immune response. When the patient relapsed, they were treated with radiosurgery and anti-CTLA4 (ipilimumab) immunotherapy (reviewed in [71]). After this treatment the patient entered a complete response and, notably, in addition to an increase in MAGEA3 antibodies the patient also showed a new antiPASD1 response.

\section{pMHC arrays}

To compare the T-cell responses in patients to the PASD1 epitopes identified by Hardwick et al. [63] and Ait-Tahar et al. [64] we have used peptide major histocompatibility complex (pMHC) or tetramer arrays. pMHC arrays were validated originally with mouse $\mathrm{T}$ cells by Soen et al. [72] and then shown to be able to detect tumour antigen specific T-cell responses in melanoma by Chen et al. [73]. The technique is able to simultaneously detect multiple $\mathrm{T}$ - cell populations, without haplotype restriction, using small numbers of $\mathrm{CD}^{+} \mathrm{T}$ cells $\left(\sim 1.2 \times 10^{6}\right.$ cells/ array) incubated for $20 \mathrm{mins}$ with pMHC (1ng per spot) spotted onto polyacrylamide gels. Briefly $\mathrm{CD}^{+} \mathrm{T}$ cells were negatively isolated from the peripheral blood of patients with cancer. When we performed the pMHC arrays, T cells were not expanded or stimulated with peptide. These "untouched" $\mathrm{T}$ cells were dyed with the lipophilic tracer DiD and incubated with arrays printed with pMHCs from more than 50 tumour-associated antigen and viral epitopes (including HLA-A ${ }^{\star} 0201 /$ CMV and Flu controls). Positive scoring of T-cell populations was only made when $\mathrm{T}$ cells were consistently bound to three of six of the same pMHC spots in two distinct regions on the array. We have now analysed PASD1 epitope recognition by $\mathrm{T}$ cells from patients with leukaemia, colon cancer, head and neck cancer and pancreatic cancer and compared the frequency of $\mathrm{T}$ cell recognition of other wellknown tumour antigen epitopes including Wilm's tumour-1 (WT1), Proteinase 3, receptor for hyaluronan-mediated motility (RHAMM) and Surviving. 
Citation: Khan G, Denniss F, Mills KI, Pulford K, Guinn B (2013) PASD1: A Promising Target for the Immunotherapy of Haematological Malignancies. J Genet Syndr Gene Ther 4: 186. doi:10.4172/2157-7412.1000186

Page 6 of 8

\section{Development of Immunotherapy Strategies Targeting PASD1}

Joseph-Pietras et al. [48] used the pDOM-epitope DNA vaccine design [74] to compare the efficacy of the whole PASD1_v1 cDNA (FL) in vaccination studies compared with the CTL PASD1(1) and PASD1(2) ${ }_{167-175}$ epitopes [64] (Table 2). The group found a greater T-cell response in HHD mice [75] to PASD1(1) than PASD1(2) in IFN $\gamma$ ELISpot assays and significant CTL killing of loaded and endogenously PASD1 positive myeloma cell lines. Vaccines containing the FL PASD1 induced greater anti-PASD1(1) responses compared with anti-PASD1(2) suggesting immunodominance. In addition the FL PASD1 vaccine could induce CTL killing of MM cells.

The DNA fusion gene vaccine has also been used to assess PASD1 analogue peptides in HHD humanized mice [63]. One of the epitopes Pa14 was shown to be capable of inducing immune responses against the modified (Pa14) and wild type (Pw8) peptides in studies using mixed lymphocyte reaction (MLR) and CTL assays. Splenocytes from vaccinated mice demonstrated in vitro cytotoxicity against myeloid leukaemia tumour cells, which were either exogenously loaded with the corresponding wild type peptide (Pw8) or presented endogenously processed PASD1 peptides. Of note mice immunised with a pDOMPw8 DNA vaccine were unable to mount a significant immune response but mice immunised with the modified peptide pDOM-Pa14 killed Pw8 loaded and endogenous PASD1 presenting targets.

Further epitopes could be identified through the immunoscreening short overlapping peptide libraries [76,77] although some of the already predicted PASD1 epitopes [63-65] remain to be more thoroughly studied in vivo.

\section{Summary}

Clinical trials targeting PASD1 have yet to be initiated however there is accumulating evidence of the utility of DNA vaccines in such settings $[78,79]$. The expression of $P A S D 1$ in a range of tumour types, especially haematological malignancies, suggests that PASD1 specifically has a role as a target for the immunotherapy of these difficult to treat cancers that do not respond well to conventional therapy and frequently lack a more suitable treatment for the removal of minimal residual disease.

Although further studies of the frequency of PASD1 protein expression in cancers will help determine the suitability of PASD1 as a target for immunotherapy; major issues are why PASD1 has such variable expression in some cell lines and primary tissues; and whether this indicates more progressed cancer cell populations within affected tissues. The role of PASD1 as a biomarker will help us to better understand its role in cancer progression. Furthermore, PASD1 expression has been shown to exist after treatment in some patients [49] highlighting it as a potential robust post-conventional therapy target. In addition increasing our understanding of the functional role of PASD1 in cancer development will help determine whether killing tumour cells which express PASD1 will impact on cancer progression in a more meaningful way than just acting as a target for immunotherapy strategies.

\section{References}

1. Vigneron N, Stroobant V, Van den Eynde BJ, van der Bruggen $P$ (2013) Database of T cell-defined human tumor antigens: the 2013 update. Cancer Immun 13: 15

2. Caballero OL, Chen YT (2009) Cancer/testis (CT) antigens: potential targets for immunotherapy. Cancer Sci 100: 2014-2021.
3. Old LJ (1981) Cancer immunology: the search for specificity--G. H. A. Clowes Memorial lecture. Cancer Res 41: 361-375.

4. Thomas CM, Sweep CG (2001) Serum tumor markers: past, state of the art, and future. Int J Biol Markers 16: 73-86.

5. Martelange V, De Smet C, De Plaen E, Lurquin C, Boon T (2000) Identification on a human sarcoma of two new genes with tumor-specific expression. Cancer Res 60: 3848-3855.

6. Tyson KL, Weissberg PL, Shanahan CM (2002) Heterogeneity of gene expression in human atheroma unmasked using cDNA representational difference analysis. Physiol Genomics 9: 121-130.

7. Türeci O, Sahin U, Zwick C, Neumann F, Pfreundschuh M (1999) Exploitation of the antibody repertoire of cancer patients for the identification of human tumor antigens. Hybridoma 18: 23-28.

8. Sahin U, Türeci O, Schmitt $H$, Cochlovius B, Johannes T, et al. (1995) Human neoplasms elicit multiple specific immune responses in the autologous host Proc Natl Acad Sci U S A 92: 11810-11813.

9. Türeci O, Usener D, Schneider S, Sahin U (2005) Identification of tumorassociated autoantigens with SEREX. Methods Mol Med 109: 137-154.

10. Türeci O, Sahin U, Schobert I, Koslowski M, Scmitt H, et al. (1996) The SSX-2 gene, which is involved in the $t(X ; 18)$ translocation of synovial sarcomas, codes for the human tumor antigen HOM-MEL-40. Cancer Res 56: 4766-4772.

11. Scanlan MJ, Chen YT, Williamson B, Gure AO, Stockert E, et al. (1998) Characterization of human colon cancer antigens recognized by autologous antibodies. Int J Cancer 76: 652-658.

12. Obata Y, Takahashi T, Sakamoto J, Tamaki H, Tominaga S, et al. (2000) SEREX analysis of gastric cancer antigens. Cancer Chemother Pharmacol 46 Suppl: S37-42.

13. Eichmuller S, Usener D, Dummer R, Stein A, Thiel D, et al. (2001) Serological detection of cutaneous T-cell lymphoma-associated antigens. Proc Natl Acad Sci U S A 98: 629-634.

14. Jäger D, Stockert E, Scanlan MJ, Güre AO, Jäger E, et al. (1999) Cancer-testis antigens and ING1 tumor suppressor gene product are breast cancer antigens: characterization of tissue-specific ING1 transcripts and a homologue gene. Cancer Res 59: 6197-6204.

15. Guinn BA, Bland EA, Lodi U, Liggins AP, Tobal K, et al. (2005) Humoral detection of leukaemia-associated antigens in presentation acute myeloid leukaemia. Biochem Biophys Res Commun 335: 1293-1304.

16. Liggins AP, Guinn BA, Hatton CS, Pulford K, Banham AH (2004) Serologic detection of diffuse large B-cell lymphoma-associated antigens. Int J Cancer 110: 563-569.

17. von Boehmer L, Mattle M, Bode P, Landshammer A, Schäfer C, et al. (2013) NY-ESO-1-specific immunological pressure and escape in a patient with metastatic melanoma. Cancer Immun 13: 12.

18. Sonpavde G, Wang M, Peterson LE, Wang HY, Joe T, et al. (2013) HLA restricted NY-ESO-1 peptide immunotherapy for metastatic castration resistan prostate cancer. Invest New Drugs

19. Scanlan MJ, Simpson AJ, Old LJ (2004) The cancer/testis genes: review, standardization, and commentary. Cancer Immun 4: 1.

20. Cheever MA, Allison JP, Ferris AS, Finn OJ, Hastings BM, et al. (2009) The prioritization of cancer antigens: a national cancer institute pilot project for the acceleration of translational research. Clin Cancer Res 15: 5323-5337.

21. Klade CS, Voss T, Krystek E, Ahorn H, Zatloukal K, et al. (2001) Identification of tumor antigens in renal cell carcinoma by serological proteome analysis. Proteomics 1: 890-898.

22. Castelli C, Storkus WJ, Maeurer MJ, Martin DM, Huang EC, et al. (1995) Mass spectrometric identification of a naturally processed melanoma peptide recognized by CD8+ cytotoxic T lymphocytes. J Exp Med 181: 363-368.

23. Guinn BA, Bullinger L, Thomas NS, Mills KI, Greiner J (2008) SSX2IP expression in acute myeloid leukaemia: an association with mitotic spindle failure in $\mathrm{t}(8 ; 21)$, and cell cycle in $\mathrm{t}(15 ; 17)$ patients. $\mathrm{Br} \mathrm{J}$ Haematol 140: 250-251.

24. Guinn BA, Gilkes AF, Mufti GJ, Burnett AK, Mills KI (2006) The tumour antigen RAGE-1 and MGEA6 are expressed more frequently in the less lineage restricted subgroups of presentation acute myeloid leukaemia. $\mathrm{Br} \mathrm{J}$ Haemato 134: $238-239$. 
Citation: Khan G, Denniss F, Mills KI, Pulford K, Guinn B (2013) PASD1: A Promising Target for the Immunotherapy of Haematological Malignancies. J Genet Syndr Gene Ther 4: 186. doi:10.4172/2157-7412.1000186

25. Guinn B, Greiner J, Schmitt M, Mills KI (2009) Elevated expression of the leukemia-associated antigen SSX2IP predicts survival in acute myeloid leukemia patients who lack detectable cytogenetic rearrangements. Blood 113 1203-1204.

26. Guinn BA, Tobal K, Mills KI (2007) Comparison of the survival implications of tumour-associated versus cancer-testis antigen expression in acute myeloid leukaemia. Br J Haematol 136: 510-512.

27. Liberante FG, Pellagatti A, Boncheva V, Bowen DT, Mills KI, et al. (2013) High and low, but not intermediate, PRAME expression levels are poor prognostic markers in myelodysplastic syndrome at disease presentation. $\mathrm{Br} \mathrm{J}$ Haemato 162: 282-285.

28. Greiner J, Schmitt M, Li L, Giannopoulos K, Bosch K, et al. (2006) Expression of tumor-associated antigens in acute myeloid leukemia: Implications for specific immunotherapeutic approaches. Blood 108: 4109-4117.

29. Cho HJ, Caballero OL, Gnjatic S, Andrade VC, Colleoni GW, et al. (2006) Physical interaction of two cancer-testis antigens, MAGE-C1 (CT7) and NYESO-1 (CT6). Cancer Immun 6: 12.

30. Glazer CA, Smith IM, Ochs MF, Begum S, Westra W, et al. (2009) Integrative discovery of epigenetically derepressed cancer testis antigens in NSCLC. PLoS One 4: e8189.

31. Simpson AJ, Caballero OL, Jungbluth A, Chen YT, Old LJ (2005) Cancer/testis antigens, gametogenesis and cancer. Nat Rev Cancer 5: 615-625.

32. Stevenson BJ, Iseli C, Panji S, Zahn-Zabal M, Hide W, et al. (2007) Rapid evolution of cancer/testis genes on the X chromosome. BMC Genomics 8: 129.

33. Zendman AJ, Ruiter DJ, Van Muijen GN (2003) Cancer/testis-associated genes: identification, expression profile, and putative function. J Cell Physio 194: 272-288.

34. Liggins AP, Guinn BA, Banham AH (2005) Identification of lymphomaassociated antigens using SEREX. Methods Mol Med 115: 109-128.

35. Liggins AP, Brown PJ, Asker K, Pulford K, Banham AH (2004) A novel diffuse large B-cell lymphoma-associated cancer testis antigen encoding a PAS domain protein. $\mathrm{Br} \mathrm{J}$ Cancer 91: 141-149.

36. Hellmich MR, Rui XL, Hellmich HL, Fleming RY, Evers BM, et al. (2000) Human colorectal cancers express a constitutively active cholecystokinin-B/gastrin receptor that stimulates cell growth. J Biol Chem 275: 32122-32128.

37. Xu Q, Bernardo A, Walker D, Kanegawa T, Mahley RW, et al. (2006) Profile and regulation of apolipoprotein $E(A p o E)$ expression in the CNS in mice with targeting of green fluorescent protein gene to the ApoE locus. J Neurosci 26: $4985-4994$.

38. Lupetti R, Pisarra P, Verrecchia A, Farina C, Nicolini G, et al. (1998) Translation of a retained intron in tyrosinase-related protein (TRP) 2 mRNA generates a new cytotoxic $T$ lymphocyte (CTL)-defined and shared human melanoma antigen not expressed in normal cells of the melanocytic lineage. J Exp Med 188: $1005-1016$

39. Chapman-Smith A, Lutwyche JK, Whitelaw ML (2004) Contribution of the Per/ Arnt/Sim (PAS) domains to DNA binding by the basic helix-loop-helix PAS transcriptional regulators. J Biol Chem 279: 5353-5362.

40. Vreede J, van der Horst MA, Hellingwerf KJ, Crielaard W, van Aalten DM (2003) PAS domains. Common structure and common flexibility. J Biol Chem 278: 18434-18439.

41. Vincent GM (1998) The molecular genetics of the long QT syndrome: genes causing fainting and sudden death. Annu Rev Med 49: 263-274.

42. Semenza GL (2000) HIF-1 and human disease: one highly involved factor Genes Dev 14: 1983-1991.

43. Denniss FA, Breslin A, Ingram W, Hardwick NR, Mufti GJ, et al. (2007) The leukaemia-associated antigen, SSX2IP, is expressed during mitosis on the surface of myeloid leukaemia cells. Br J Haematol 138: 668-669.

44. Cooper CD, Liggins AP, Ait-Tahar K, Roncador G, Banham AH, et al. (2006) PASD1, a DLBCL-associated cancer testis antigen and candidate for lymphoma immunotherapy. Leukemia 20: 2172-2174.

45. Yee C, Biondi A, Wang XH, Iscove NN, de Sousa J, et al. (1989) A possible autocrine role for interleukin-6 in two lymphoma cell lines. Blood 74: 798-804.

46. Kamesaki H, Fukuhara S, Tatsumi E, Uchino H, Yamabe H, et al. (1986)
Cytochemical, immunologic, chromosomal, and molecular genetic analysis of a novel cell line derived from Hodgkin's disease. Blood 68: 285-292.

47. Klein E, Ben-Bassat H, Neumann H, Ralph P, Zeuthen J, et al. (1976) Properties of the K562 cell line, derived from a patient with chronic myeloid leukemia. In J Cancer 18: 421-431.

48. Joseph-Pietras D, Gao Y, Zojer N, Ait-Tahar K, Banham AH, et al. (2010) DNA vaccines to target the cancer testis antigen PASD1 in human multiple myeloma. Leukemia 24: 1951-1959.

49. Sahota SS, Goonewardena CM, Cooper CD, Liggins AP, Ait-Tahar K, et al (2006) PASD1 is a potential multiple myeloma-associated antigen. Blood 108 3953-3955.

50. Liggins AP, Lim SH, Soilleux EJ, Pulford K, Banham AH (2010) A panel of cancer-testis genes exhibiting broad-spectrum expression in haematological malignancies. Cancer Immun 10: 8.

51. van Duin M, Broyl A, de Knegt Y, Goldschmidt H, Richardson PG, et al. (2011) Cancer testis antigens in newly diagnosed and relapse multiple myeloma: prognostic markers and potential targets for immunotherapy. Haematologica 96: $1662-1669$

52. Guinn BA, Gilkes AF, Woodward E, Westwood NB, Mufti GJ, et al. (2005) Microarray analysis of tumour antigen expression in presentation acute myeloid leukaemia. Biochem Biophys Res Commun 333: 703-713.

53. Ghafouri-Fard S, Abbasi A, Moslehi H, Faramarzi N, Taba Taba Vakili S, et al. (2010) Elevated expression levels of testis-specific genes TEX101 and SPATA19 in basal cell carcinoma and their correlation with clinical and pathological features. Br J Dermatol 162: 772-779.

54. Hans CP, Weisenburger DD, Greiner TC, Gascoyne RD, Delabie J, et al. (2004) Confirmation of the molecular classification of diffuse large B-cell lymphoma by immunohistochemistry using a tissue microarray. Blood 103: 275-282.

55. Dunn GP, Old LJ, Schreiber RD (2004) The three Es of cancer immunoediting Annu Rev Immunol 22: 329-360.

56. Matzinger $P$ (1994) Tolerance, danger, and the extended family. Annu Rev Immunol 12: 991-1045

57. Dai YD, Carayanniotis G, Sercarz E (2005) Antigen processing by autoreactive B cells promotes determinant spreading. Cell Mol Immunol 2: 169-175.

58. Szczepanski MJ, DeLeo AB, Å uczak M, Molinska-Glura M, Misiak J, et al. (2013) PRAME expression in head and neck cancer correlates with markers of poor prognosis and might help in selecting candidates for retinoid chemoprevention in pre-malignant lesions. Oral Oncol 49: 144-151.

59. Sturniolo T, Bono E, Ding J, Raddrizzani L, Tuereci O, et al. (1999) Generation of tissue-specific and promiscuous HLA ligand databases using DNA microarrays and virtual HLA class II matrices. Nat Biotechnol 17: 555-561.

60. Rammensee H, Bachmann J, Emmerich NP, Bachor OA, StevanoviÄ S (1999) SYFPEITHI: database for MHC ligands and peptide motifs. Immunogenetics 50: 213-219.

61. Parker KC, Bednarek MA, Coligan JE (1994) Scheme for ranking potentia HLA-A2 binding peptides based on independent binding of individual peptide side-chains. J Immunol 152: 163-175.

62. Alexander J, Payne JA, Murray R, Frelinger JA, Cresswell P (1989) Differentia transport requirements of HLA and $\mathrm{H}-2$ class I glycoproteins. Immunogenetics 29: 380-388.

63. Hardwick N, Buchan S, Ingram W, Khan G, Vittes G, et al. (2013) An analogue peptide from the Cancer/Testis antigen PASD1 induces CD8+ T cell responses against naturally processed peptide. Cancer Immun 13: 16

64. Ait-Tahar K, Liggins AP, Collins GP, Campbell A, Barnardo M, et al. (2009) Cytolytic T-cell response to the PASD1 cancer testis antigen in patients with diffuse large B-cell lymphoma. Br J Haematol 146: 396-407.

65. Ait-Tahar K, Liggins AP, Collins GP, Campbell A, Barnardo M, et al. (2011) CD4-positive T-helper cell responses to the PASD1 protein in patients with diffuse large B-cell lymphoma. Haematologica 96: 78-86.

66. Rezvani K, Yong AS, Tawab A, Jafarpour B, Eniafe R, et al. (2009) Ex vivo characterization of polyclonal memory CD8+ T-cell responses to PRAME specific peptides in patients with acute lymphoblastic leukemia and acute and chronic myeloid leukemia. Blood 113: 2245-2255.

67. Mougiakakos D, Jitschin R, von Bahr L, Poschke I, Gary R, et al. (2013) 
Citation: Khan G, Denniss F, Mills KI, Pulford K, Guinn B (2013) PASD1: A Promising Target for the Immunotherapy of Haematological Malignancies. J Genet Syndr Gene Ther 4: 186. doi:10.4172/2157-7412.1000186

Immunosuppressive CD14+HLA-DRlow/neg IDO+ myeloid cells in patients following allogeneic hematopoietic stem cell transplantation. Leukemia 27 377-388

68. Buggins AG, Patten PE, Richards J, Thomas NS, Mufti GJ, et al. (2008) Tumorderived IL-6 may contribute to the immunological defect in CLL. Leukemia 22: 1084-1087.

69. Wendelbo $\varnothing$, Nesthus I, Sjo M, Paulsen K, Ernst P, et al. (2004) Functional characterization of $\mathrm{T}$ lymphocytes derived from patients with acute myelogenous leukemia and chemotherapy-induced leukopenia. Cancer Immunol Immunother 53: $740-747$

70. Stamell EF, Wolchok JD, Gnjatic S, Lee NY, Brownell I (2013) The abscopal effect associated with a systemic anti-melanoma immune response. Int $\mathrm{J}$ Radiat Oncol Biol Phys 85: 293-295.

71. Wolchok JD, Hodi FS, Weber JS, Allison JP, Urba WJ, et al. (2013) Development of ipilimumab: a novel immunotherapeutic approach for the treatment of advanced melanoma. Ann N Y Acad Sci 1291: 1-13.

72. Soen Y, Chen DS, Kraft DL, Davis MM, Brown PO (2003) Detection and characterization of cellular immune responses using peptide-MHC microarrays. PLoS Biol 1: E65.

73. Chen DS, Soen Y, Stuge TB, Lee PP, Weber JS, et al. (2005) Marked differences in human melanoma antigen-specific $T$ cell responsiveness after vaccination using a functional microarray. PLoS Med 2: e265.
74. Rice J, Ottensmeier CH, Stevenson FK (2008) DNA vaccines: precision tools for activating effective immunity against cancer. Nat Rev Cancer 8: 108-120.

75. Firat H, Garcia-Pons F, Tourdot S, Pascolo S, Scardino A, et al. (1999) $\mathrm{H}-2$ class I knockout, HLA-A2.1-transgenic mice: a versatile animal mode for preclinical evaluation of antitumor immunotherapeutic strategies. Eur $\mathrm{J}$ Immunol 29: 3112-3121.

76. Komatsu N, Jackson HM, Chan KF, Oveissi S, Cebon J, et al. (2013) Finemapping naturally occurring NY-ESO-1 antibody epitopes in melanoma patients' sera using short overlapping peptides and full-length recombinan protein. Mol Immunol 54: 465-471.

77. Lewinsohn DM, Swarbrick GM, Cansler ME, Null MD, Rajaraman V, et al (2013) Human Mycobacterium tuberculosis CD8 T Cell Antigens/Epitopes Identified by a Proteomic Peptide Library. PLoS One 8: e67016.

78. Chudley L, McCann K, Mander A, Tjelle T, Campos-Perez J, et al. (2012) DNA fusion-gene vaccination in patients with prostate cancer induces highfrequency CD8(+) T-cell responses and increases PSA doubling time. Cance Immunol Immunother 61: 2161-2170.

79. Low L, Mander A, McCann K, Dearnaley D, Tjelle T, et al. (2009) DNA vaccination with electroporation induces increased antibody responses in patients with prostate cancer. Hum Gene Ther 20: 1269-1278.
Citation: Khan G, Denniss F, Mills KI, Pulford K, Guinn B (2013) PASD1: A Promising Target for the Immunotherapy of Haematological Malignancies. J Genet Syndr Gene Ther 4: 186. doi:10.4172/2157-7412.1000186
Submit your next manuscript and get advantages of OMICS Group submissions

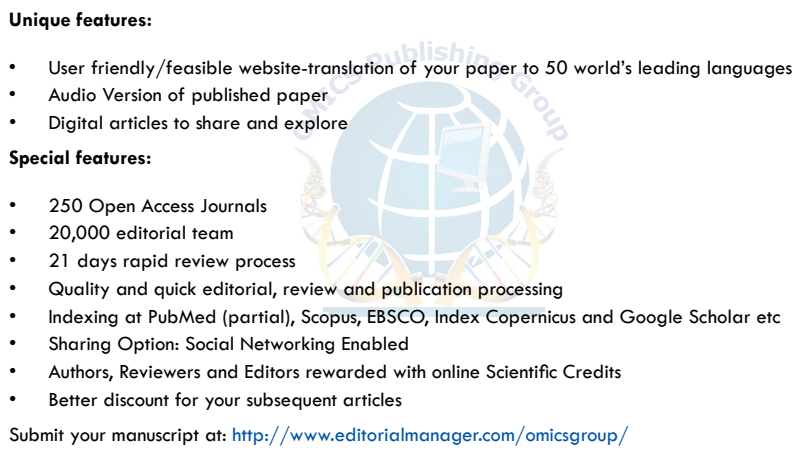

